\title{
ALL COUNTRIES, GREAT AND SMALL
}

Undaunted by the scientific dominance of historic global big-hitters, some of the world's less prominent research nations are carving out a niche and making a strong impact.

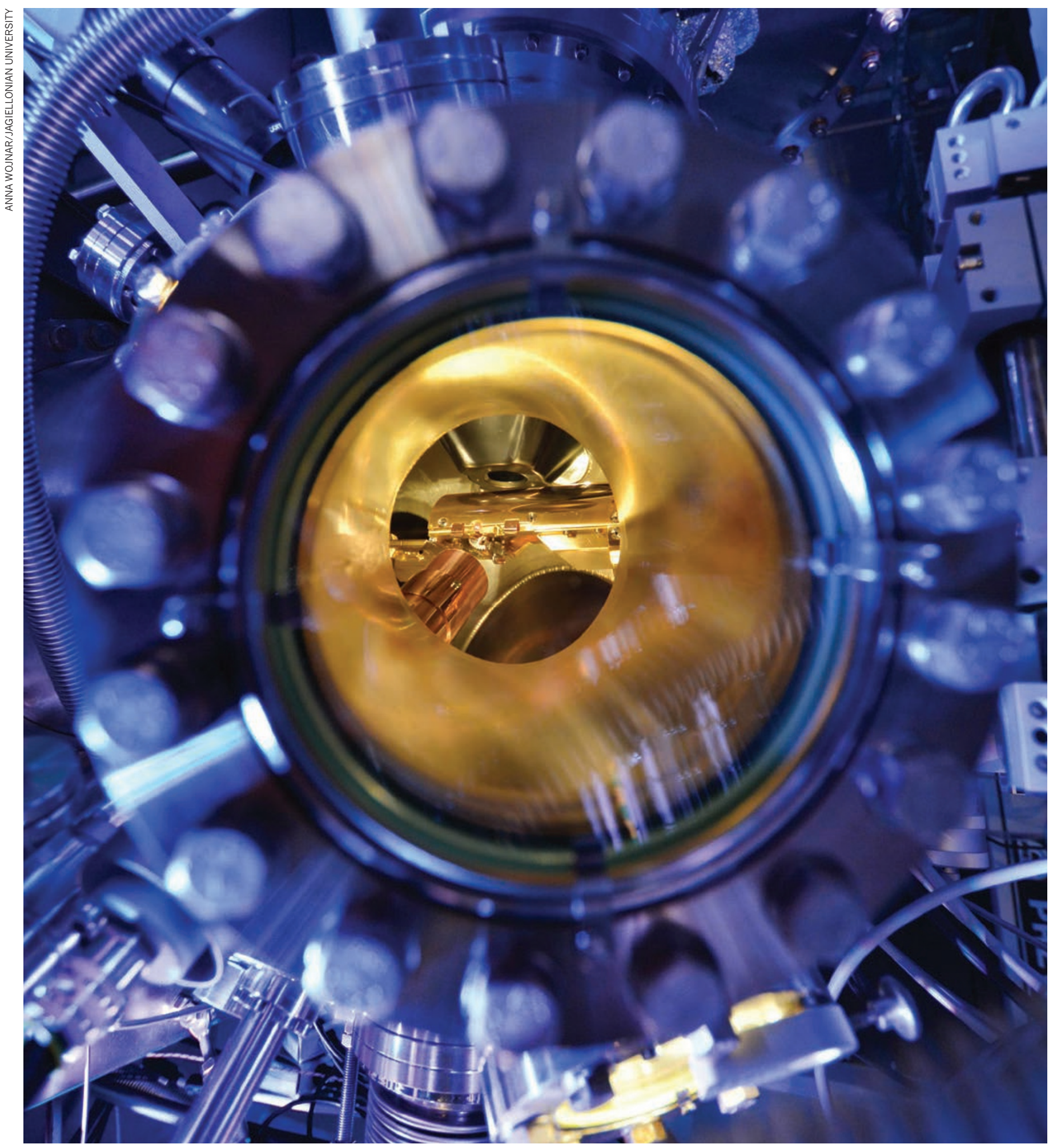

The Solaris Synchrotron at Jagiellonian University in Poland began operating in 2015 and was made possible by generous EU funding. 
A large portion of the world's best science is produced by a few players: the United States, China, Japan, France, Germany and the United Kingdom. These countries contribute the most to the 68 top-tier natural science journals included in the Nature Index. But, look beyond these heavyweights, and several countries have improved their research performance more than most. These are the ones to watch in 2016 and beyond.

Our selection of rising stars is based on the rate of increase in a country's contribution to 68 index journals, a metric known as weighted fractional count (WFC). The countries listed experienced some of the highest absolute and percentage increases - in either their overall WFC or in a specific subject area - between 2012 and 2015.

\section{POLAND}

\section{WFC: 176.77}

\section{WFC: 237.42}

Thanks to generous European Union support and a new competitive funding regime, Poland's contribution to the index leapt 34\% between 2012 and 2015. The increase can be largely credited to the 2011 creation of the national competitive funding body for basic science, the National Science Centre, and the reform of its applied science counterpart, the National Centre for Research and Development. "The funds spent on science are now highly competitive. This is a huge change," says molecular biologist, Maciej Zylicz, president of the Foundation for Polish Science. As a result, the proportion of funding distributed through competitive grants has risen from $13 \%$ before the changes to $45 \%$, or nearly $€ 1.8$ billion in 2014-15, a trend that is likely to continue as the government moves to have all taxpayer funding of science awarded on the basis of performance. In practice, these reforms have brought particular gains, mainly in the physical sciences, which has long been Poland's strongest area and which made up more than half of the country's contribution to the index in 2015.

In recent years, Polish scientists have also benefited from new facilities for research. Generous EU funding for research and innovation, $€ 14$ billion between 2007 and 2013, has led to the creation of 10 new international research centres since 2007, including the Solaris Synchrotron at Kraków’s Jagiellonian University, which began operation in 2015. AM

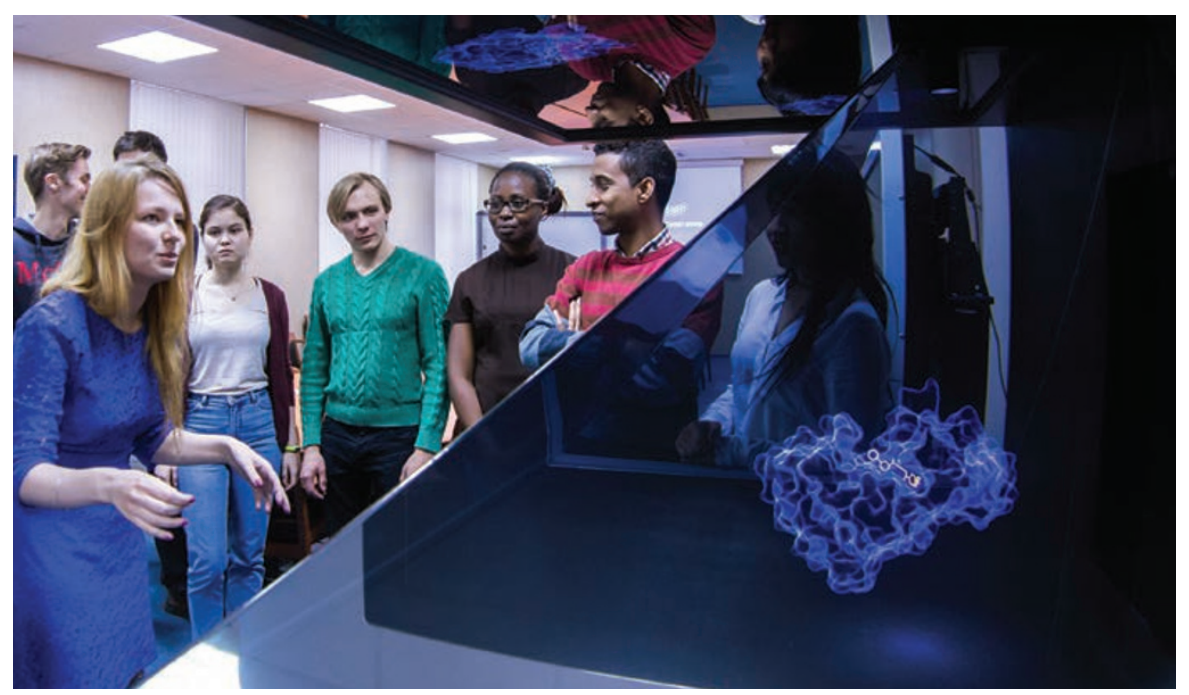

A promovisor reveals a matching ligand being selected for a cancer protein at St Petersburg's ITMO University, which specializes in IT, optical design and engineering.

\section{RUSSIA}

\section{WFC: 298.28}

\section{WFC: 370.39}

The Russian share of the world's high-quality research increased dramatically between 2012 and 2015. The country's contribution to life sciences in particular grew by more than $60 \%$, the largest percentage rise among the top 10 countries in this field.

These results come at a time of continuing upheaval in the country's science community. Since 2013, the Russian Academy of Sciences (RAS), a 300-year-old network of more than 500 research institutes, has been

\section{RISING STARS}

Russia, Poland and Saudi Arabia experienced some of the highest percentage increases in their contribution to this index, a metric known as WFC between 2012 and 2015. AC is the total number of articles included in the index.

\section{Russia Poland Saudi Arabia}

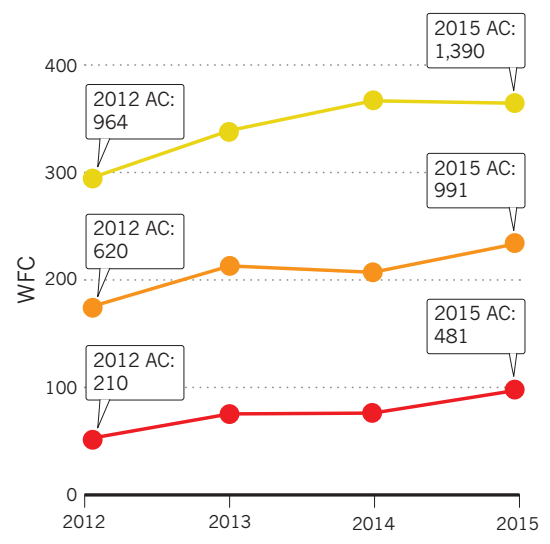

"Russia's strong results come at a time of continuing upheaval in the country's science community." undergoing a radical, Kremlin-driven overhaul that many believe will result in the closure of a large swathe of its institutes. Already, RAS has ceded control of its research priorities and budgets to a separate government agency. And while RAS remains Russia's top producer of high-quality research, its share of the country's index contribution slipped by $2 \%$ between 2012 and 2015. Overall, the contribution of Russian scientists to the index increased by $24 \%$ over the same period.

By contrast, initiatives to generate quality research outcomes in the university sector are showing signs of success with contributions from the sector driving the country's rising star status. The most ambitious such initiative is the 5-100 Project, launched in 2013 with the aim of pushing five of Russia's top research universities into the top global rankings by 2020 . The project has steered significant additional resources to 21 leading universities. The results are manifest in the index: of the 10 Russian institutions with the highest overall index score, seven are part of the 5-100 programme. Second on the list is St Petersburg's ITMO University, which specializes in IT, optical design and engineering, and saw a leap of $184 \%$ in its WFC.

Research in the physical sciences continues to dominate Russian research, but performance in the life sciences is rapidly improving. The RAS led the gain in quality life sciences publications - an outcome most likely abetted by its absorption of the Russian Academy of Medical Sciences and the Russian Academy of Agricultural Sciences under the 2013 reforms. 
Larger economic forces continue to weigh down Russian science activity. In particular, the research community is increasingly feeling the funding pinch caused by the falling oil price and the ongoing domestic economic malaise, says science policy analyst, Irina Dezhina. “The total expenditure on R\&D has decreased by $10 \%$ this year and there will probably be an additional decrease in the coming year," Dezhina says. AM

\section{SAUDI ARABIA}

\section{WFC: 52.82 \\ 2015 WFC: 98.80}

Saudi Arabia will remain the world's biggest exporter of oil for many years to come. But, its government has ambitious plans to reduce oil dependence and develop a knowledge-led economy. Signs of its reinvention can already be seen in the kingdom's research - Saudi contribution to high-quality research almost doubled over the past four years. Authors from 40 organizations in the kingdom have had their research published in index journals over four years.

Saudi Arabia's major leaps have been in chemistry and, perhaps surprisingly, in Earth and environmental sciences. The leader in this domain is the King Abdul-

lah University of Science and Technology (KAUST), which was established in 2009 on the Red Sea coast, and which has made marine research one of its main focuses. An example is a recent paper in Nature detailing the genome of eelgrass, the first marine angiosperm to be fully sequenced. To unravel this organism's genome, Carlos Duarte, a marine scientist at KAUST, engaged in a long-term collaboration with more than 30 international researchers. The findings may help explain how marine ecosystems are adapting to cli-

"The Saudi government has ambitious plans to build a knowledgeledeconomy." mate change knowledge that may have ramifications for human efforts to mitigate this looming environmental threat.

Seagrasses are a neglected group of higher plants, but are important because they are the only marine plants that fully colonize the sea.

Another effort to boost international collaboration was a partnership with Stanford University that developed a dexterous humanoid robot to inspect coral reefs that are too deep for human divers to explore. It also has a haptic feedback system and can be used to explore wrecks. TH

\section{DENMARK}

\section{WFC LIFE SCIENCES: 97.94 \\ 2015 WFC LIFE SCIENCES: 114.48}

Denmark's contribution to life science in the index grew 17\% between 2012 and 2015. The boost is helped by access to one of the world's leading health data sets much of it stored and distributed by the State Serum Institute - good government support, and strong engagement by Danish pharmaceutical companies, including Novo Nordisk, Lundbeck and Leo Pharma.

"The Danish community understands that research matters. Government and business are aware that good science is competitive and needs funding and good leadership," says Ulla Wewer, dean of the Faculty of Health and Medical Sciences at the University of Copenhagen.

OECD data reveals government funding for R\&D has steadily increased as a proportion of GDP for more than a decade and it is now one of the highest in Europe at just over $3 \%$ (for a total of more than US\$7 billion). Life sciences research has benefitted strongly from this, as well as from generous support from private foundations established by the country's homegrown pharmaceutical giants.

The University of Copenhagen leads the improvement in the index showing a nearly $20 \%$ increase in contributions to high-quality life science research from 2012 to 2015 . The university is already Denmark's leading life sciences performer and a strong international player. "We follow Pasteur's motto: find the best people,

\section{WELL MIXED}

While Denmark is a rising star in life sciences, in 2015 the country's WFC in chemistry and physical sciences made up a significant portion of its index contribution.

\section{Chemistry}

Earth and environmental sciences

Life sciences

Physical sciences

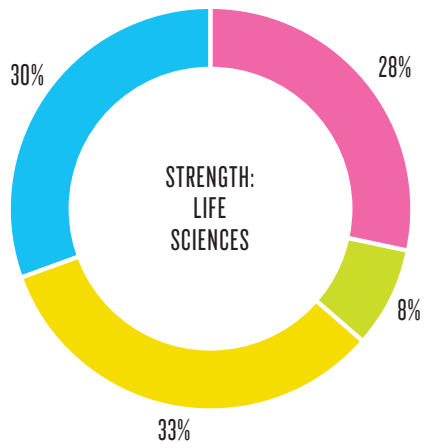

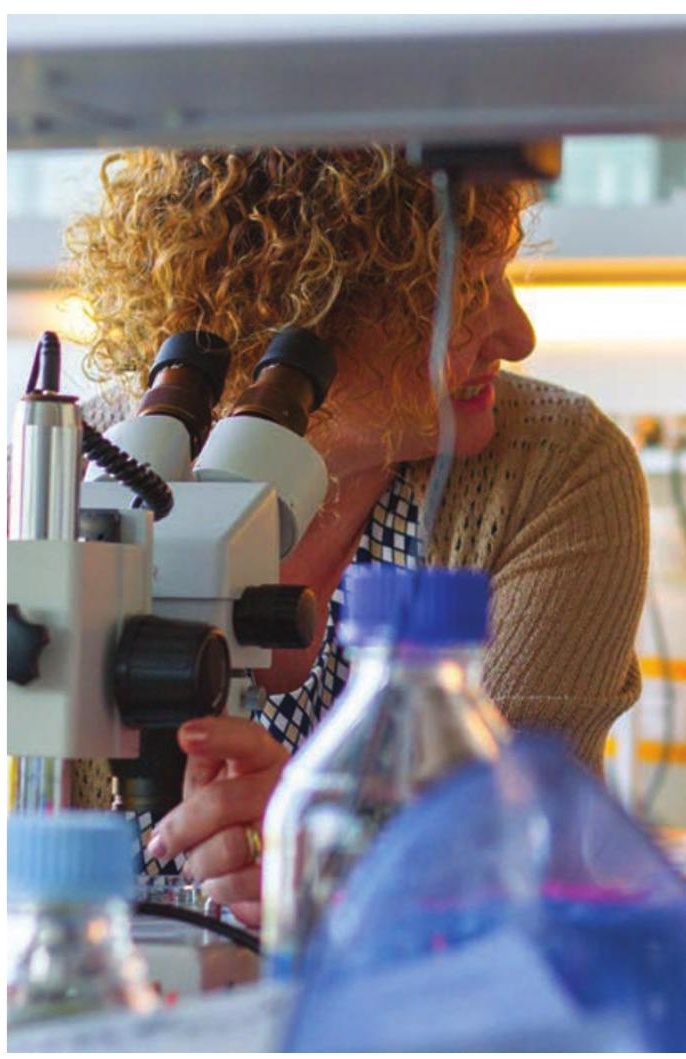

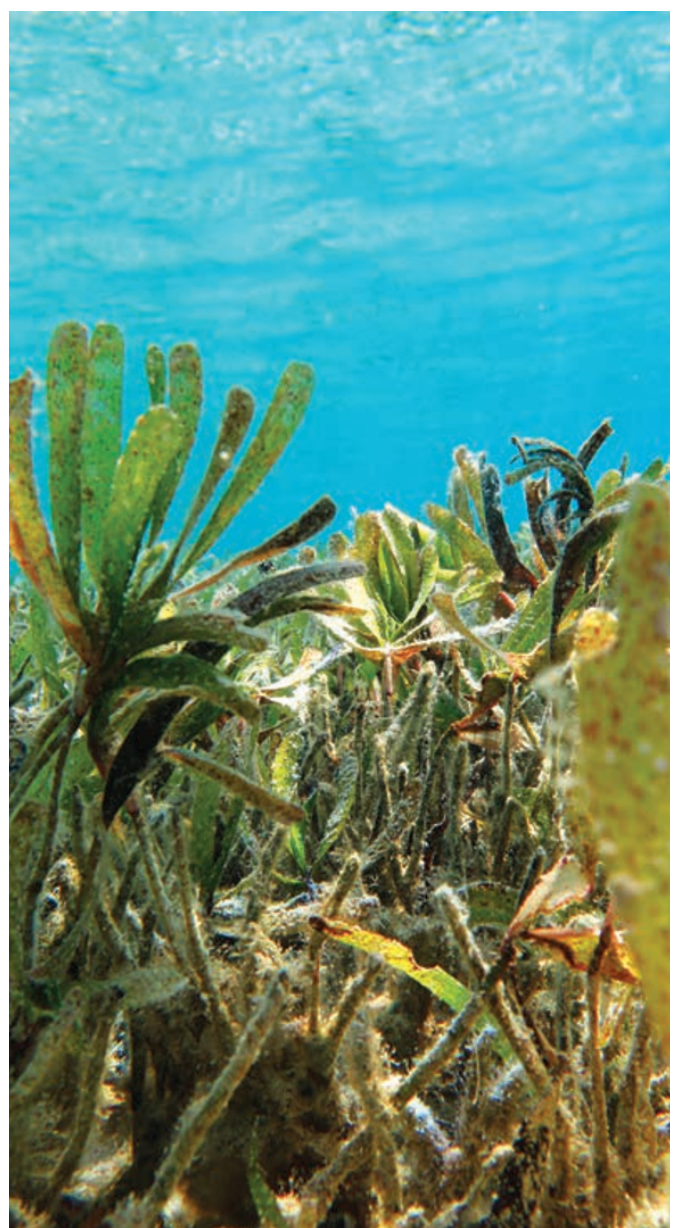

Top: Shohreh Issazade (left) and her colleague at the University of Copenhagen. Left: A seagrass meadow studied by KAUST in the Red Sea. 


\section{CHILE}

\section{WFC PHYSICAL SCIENCES: 49.65}

\section{WFC PHYSICAL SCIENCES: 68.05}

Last year, thousands of scientists, technicians and students took to the streets to protest the Chilean government's poor research investment. According to the World Bank, the most recent data available (2012) show that Chile spent less than $0.5 \%$ of its GDP on R\&D - significantly less than the $1.15 \%$ by Brazil and Argentina's $0.58 \%$. About $80 \%$ of scientific research in Chile is publicly funded.

Despite limited investment, Chile's contribution to physical sciences research in the index grew by almost $40 \%$ between 2012 and 2015. Thanks to the clear skies of the Atacama Desert, the country hosts some of the world's biggest telescopes, including the European Southern Observatory's Very Large Telescope. Chile is growing in areas besides astronomy. Researchers discovered a new dinosaur, a raptor-like vegetarian relative of Tyrannosaurus rex, that lived during the Late Jurassic period. 'Chilesaurus', became one of the most sensational palaeontology stories of 2015 with the findings published in Nature.

"We experience the frustration of producing top-notch work, yet being unable to obtain the funding we need to research and protect our fossil heritage," says a researcher at the University of Chile, Alex Vargas, one of the team that documented Chilesaurus. "The University of Chile has been our main support. It recognized our excellence." This recognition, Vargas says, came through direct grants and by help with application for larger grants from other funding sources.

\section{ASTRONOMICAL ADVANTAGE}

A strong focus on astronomy helped boost Chile's physical sciences WFC between 2012 and 2015.

\section{Chemistry}

Earth and environmental sciences

Life sciences

Physical sciences

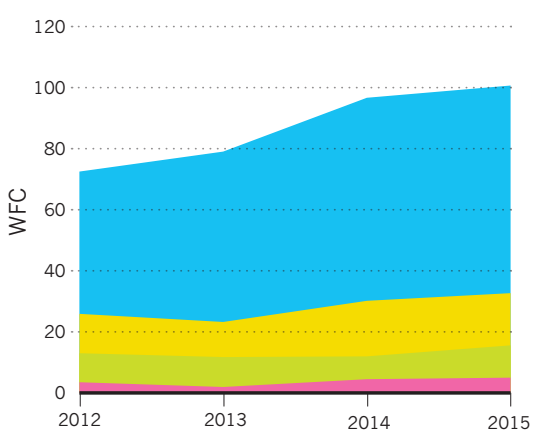

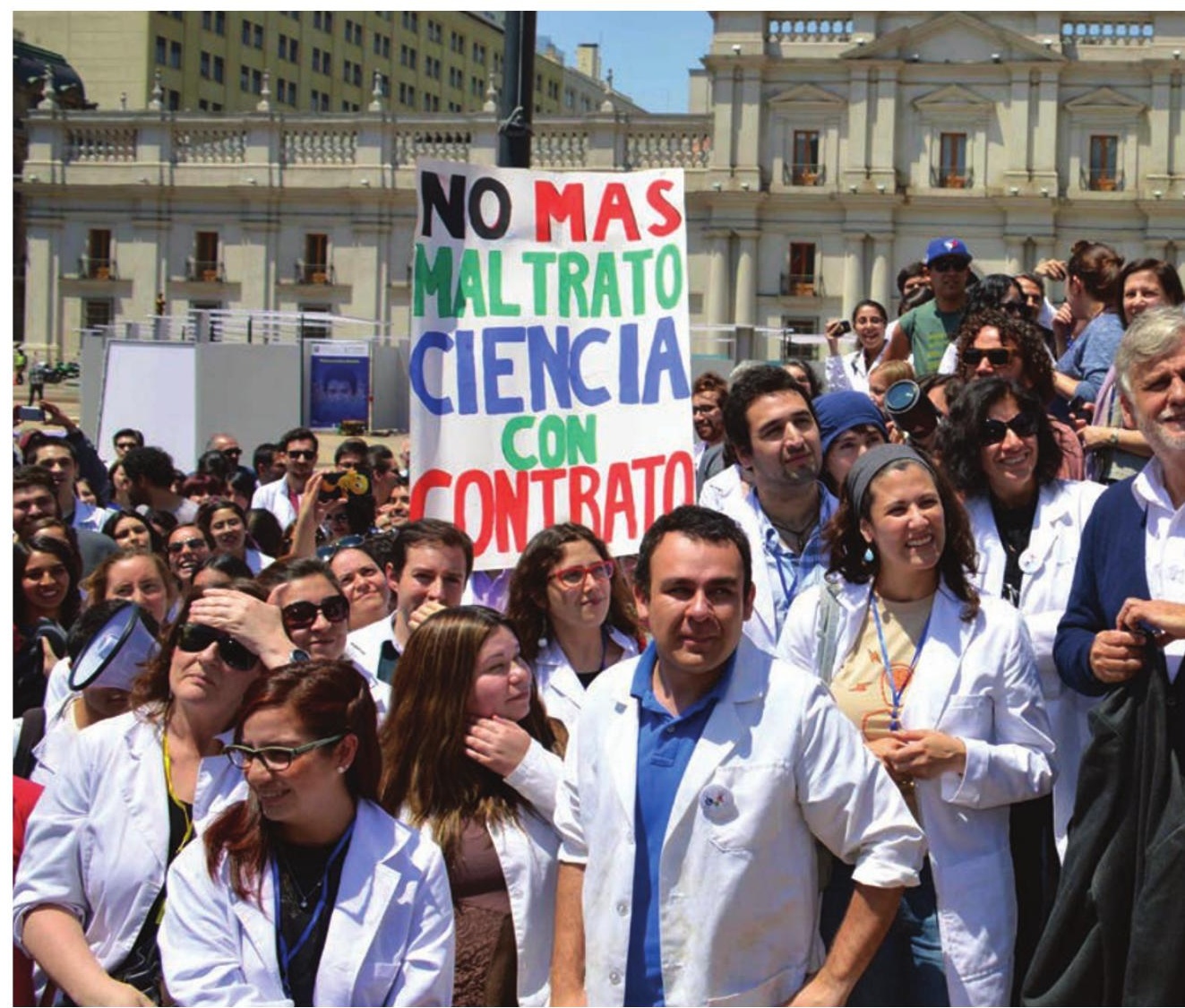

Chilean scientists rally at the Government Palace in Santiago, to protest the government's poor research investment, significantly less than the proportion spent by its neighbours.

Chile's National Commission for Scientific and Technological Research (CONICYT), a funding agency, is part of the Ministry of Education and acts in lieu of a science ministry. In the past, the commission has been responsible for more than $50 \%$ of publicly funded science research in Chile; in 2016, it had a budget of US $\$ 442$ million.Mario Hamuy, an astronomer at the University of Chile and chairman of CONICYT, says public investment in scientific research overall has more than doubled since 2007, and that the budget for fundamental research has tripled. Chilean president, Michelle Bachelet, also gave Hamuy the job of creating a science and technology ministry that would define and implement policies. TH

\section{SINGAPORE}

\section{WFC CHEMISTRY: 227.80}

\section{WFC CHEMISTRY: 296.04}

Singapore's research performance has improved markedly in life sciences and chemistry. The city-state, with a population of only 5.5 million, also more than doubled its contribution to Earth and environmental science journals between 2012 and 2015, albeit off a low base.

With English as the primary language taught in schools, Singaporeans have an advantage in international collaborations. The country also has a steady pipeline of scientists-in-training, about 8,000 doctorate researchers in 2015.

It also benefits from long-term planning and generous science funding, which is done in five-year tranches. In January 2016, Prime Minister Lee Hsien Loong announced a new Research, Innovation and Enterprise plan that sets aside US $\$ 13.8$ billion for research investment to 2020 . That's an $18 \%$ increase over the previous one, giving Singapore the world's highest per capita investment in science and technology. The 2016 plan has four pillars: advanced manufacturing and engineering; health and biomedical sciences; urban solutions and sustainability; and services and digital economy.

Singapore has a strong focus on water research, which is driven by water scarcity on its islands. Scientists, led by teams at Nanyang Technology University and the National University of Singapore, have spent decades working with Singapore's Public Utilities Board developing ways to reclaim wastewater using membrane technologies and ultraviolet disinfection techniques. 
